\title{
CORTESIA, DESCORTESIA E ATIVIDADE DE IMAGEM: UMA ANÁLISE DOS COMENTÁRIOS DE FACEBOOK PUBLICADOS NAS PÁGINAS DOS PRESIDENTES DO BRASIL E DE PORTUGAL
}

\section{MARIANA SANTOS ANDRADE}

Mestranda em Letras pela Universidade Presbiteriana Mackenzie (UPM), São Paulo, SP, Brasil.

E-mail: mariana_s.a@hotmail.com

\section{Resumo}

O uso das línguas é orientado por diversos fatores, que podem ser também de ordem cultural. Sabe-se que a língua portuguesa, por exemplo, tem características próprias manifestadas nos diferentes países em que é falada. Dessa forma, este artigo buscou apontar as diferenças do uso dessa língua em relação à cortesia, descortesia e atividades de imagem empregadas em comentários de Facebook relacionados à política e elaborados em português brasileiro e europeu, colocando em evidência a relação entre língua, cultura e identidade.

\section{Palavras-chave}

Cortesia. Lusofonia. Discurso político. 


\section{INTRODUÇÃO}

O uso de uma língua está intrinsecamente ligado à maneira com a qual os falantes se expressam como indivíduos. Uma vez que manifesta valores e ideologias, e age como mediadora entre o sujeito e a realidade, ela pode ser utilizada de inúmeras formas, expondo diferentes culturas advindas de diversos povos, como ocorre com as expressões encontradas no português do Brasil e Portugal.

Dessa forma, este artigo pretende mostrar como dois países pertencentes ao universo lusófono utilizam a língua como representação de suas realidades, e como esse uso colabora para a construção da identidade de seus povos. Para atingir esse objetivo, o corpus dessa pesquisa é composto pelas páginas da rede social Facebook que representam a presidente eleita no Brasil, Dilma Rousseff, que ocupou o cargo da presidência de 2011 a 2016, e o presidente de Portugal, Marcelo Rebelo de Sousa, que está no cargo desde 2016. Serão analisadas as atividades de imagem elaboradas nas redes sociais dos presidentes, além de interações que acontecem nos comentários feitos pelos membros de ambas as páginas, tendo por embasamento teórico principal os estudos sobre cortesia, descortesia e atividade de imagem.

\section{LUSOFONIA, CULTURA E IDENTIDADE}

Compreende-se por lusofonia o grupo de falantes da língua portuguesa que a utilizam como língua mãe. Esse fenômeno se caracteriza como um "espaço" cultural, uma vez que se articula de diferentes modos a partir de uma língua comum. Ainda, deve-se apontar que a presença do português em múltiplos lugares torna a língua enriquecida por variantes que vieram transformando o padrão europeu no decorrer do tempo. De acordo com Brito (2013, p. 30), a Lusofonia

[...] só pode fazer sentido se concebida como um espaço simbólico, linguístico e cultural, cuja identidade se constrói em movimento, numa dinâmica de conhecimento e reconhecimento identitários. Assim, apontamos para uma conceituação de Lusofonia desvinculada de egocentrismos e/ou desconfortos que o termo por vezes carrega, em discursos anacrônicos, e que a associam a posturas neocolonialistas, por sua identificação com uma centralidade da matriz portuguesa em relação aos sete outros membros da Comunidade dos 
Países de Língua Portuguesa. Uma lusofonia plausível não pode estar atrelada às excrescências do passado e encerrar-se numa exclusiva centralidade. Deve, sim, assumir os diversos centros que a mantêm possível hoje e que a projetam para o futuro, em decorrência de afinidades históricas, culturais e linguísticas.

Deve-se apontar que a língua e a cultura são elementos que colaboram para a construção identitária. Assim, pode-se dizer que a lusofonia se relaciona a aspectos da identidade cultural. A identidade pode ser compreendida, primeiramente, como aquilo que diferencia um sujeito do outro, a partir de sua origem, língua que fala, história, entre outras características. É um termo presente no cotidiano como aquilo que define os indivíduos. Pode estar relacionada, também, aos papéis que esse sujeito cumpre no coletivo e suas características pessoais.

O sociólogo Stuart Hall (1996) traz a questão da identidade fragmentada do sujeito pós-moderno, que expressa seus aspectos identitários e culturais de forma mais diferenciada, mais problemática e mais contraditória. É possível, então, compreender a identidade como um conceito que envolve questões relativas à imagem que o indivíduo cria de si mesmo e à imagem que a sociedade tem sobre esse mesmo indivíduo. Assim como a cultura, que é inserida em um constante processo de mudanças, a noção identitária do sujeito pós-moderno também está sempre em progressão.

\section{ATIVIDADE DE IMAGEM, CORTESIA E DESCORTESIA}

O termo "imagem" aparece inicialmente na obra do sociólogo Goffman (1967, p. 77 ) como "o valor social positivo que uma pessoa reclama para si mesma através daquilo que os outros presumem ser a linha por ela tomada durante um contato específico".

Brown e Levinson (1987, p. 61), embora tenham sido alvo de revisões, como por - Bravo (2004a; 2004b) e Hernández Flores (2004), propuseram um complemento de grande repercussão para esse conceito, defendendo que a imagem pode ser negativa ou positiva, sendo que a primeira está relacionada à intenção de manter um território próprio e pessoal, que possui liberdade e não sofre imposições, enquanto a segunda diz respeito a uma fachada social que é criada a partir da interação. 
Bravo (1999) propõe a existência de necessidades humanas vinculadas à imagem: a autonomia, que está relacionada à maneira com a qual o indivíduo percebe a si mesmo, e como os demais o percebem como alguém com um espaço próprio dentro de determinado grupo, e a afiliação, que é tudo aquilo que colabora para que o indivíduo se identifique com os demais, inclusive o que faz com que as outras pessoas o percebam como parte de um grupo.

A linguista diz que, por se tratarem de princípios humanos, supostamente seriam universais, ao contrário da divisão imagem positiva e negativa. Além disso, o que diferencia a proposta de Bravo (1999) da noção construída por Brown e Levinson (1987), é que esses conceitos não devem ser vistos como categorias de diferenciação, mas sim como categorias inicialmente vazias, que devem ser preenchidas no processo de análise de acordo com os contextos socioculturais.

Os indivíduos apresentam alguns desejos de imagem, ou seja, querem que suas imagens sejam respeitadas e reconhecidas pelo grupo social no qual se inserem. Existem algumas estratégias que podem ser utilizadas como ferramentas para satisfazer os desejos de imagem, as quais Goffman (1967) chamou de face work (atividade de imagem), sendo a cortesia e a descortesia tipos possíveis de atividade de imagem.

Hernández Flores (2004) afirma que a cortesia é, também, usada para realçar a imagem, considerando esse como um dos motivos que fazem com que um falante seja cortês. Dessa forma, essa atividade social traz benefício mútuo às imagens, sendo que serve tanto para fazer com que o ouvinte se sinta bem quanto em benefício do próprio falante. Dessa forma,

\begin{abstract}
O comportamento cortês refere-se a alcançar uma situação de equilíbrio entre a imagem social do destinatário e a do falante, de forma que ambas sejam beneficiadas em algum grau, o qual consiste em confirmar seus desejos de imagem em relação aos papéis que estão desempenhando.' (HERNÁNDEZ FLORES, 2004, p. 100, tradução nossa).
\end{abstract}

Ao contrário do que ocorre com a cortesia, a descortesia é a busca em denegrir a imagem do coenunciador, prejudicando, possivelmente, a própria imagem no processo de acordo com o contexto no qual é utilizada.

1 el comportamiento cortés trata de alcanzar una situación de equilibrio entre la imagen social del destinatario y la del hablante, de forma que ambas se vean beneficiadas en algún grado, lo cual consiste en confirmar sus deseos de imagen en relación con los roles que están desempeñando. 


\section{DISCURSO POLÍTICO NO FACEBOOK}

A linguagem utilizada no discurso político deve seguir regras previamente estabelecidas, como acontece em quaisquer tipos de interação, em maior ou menor grau de formalidade, com o propósito de atingir determinados objetivos. Nesse contexto, Charaudeau (2015) aponta para a existência de uma ação política, que determina e organiza a vida em sociedade, objetivando o bem comum e permitindo que a comunidade tome decisões em conjunto.

O autor defende a existência de uma instância política, uma cidadã e uma midiática, sendo que, na primeira, acontece a manipulação como tentativa de chegar ou de continuar no poder, na segunda, a sociedade capacita-se para eleger o candidato mais adequado, e, na terceira, refere-se aos modos de mediação utilizados para unir as instâncias política e cidadã, tais como panfletos, cartazes e demais veículos de informação.

Atualmente, na instância midiática, nota-se um crescimento na adoção das redes sociais como estratégia para o marketing político, considerando o grande alcance que têm no cotidiano das pessoas. Em meio às possibilidades, o Facebook ganha destaque por permitir a interação entre aqueles que acessam as páginas e seus devidos administradores ou, até mesmo, entre os próprios usuários, proporcionando uma comunicação mais direta, o que possibilita a chance de o político melhorar sua imagem diante do público eleitor, considerando, ainda, que a rede social é utilizada, também, como meio de promover a própria imagem, seja ela de uma marca ou de um indivíduo - político.

As redes sociais são ferramentas de comunicação que podem ser utilizadas por quaisquer pessoas, grupos, entidades ou instituições. O Facebook permite a criação de uma página de perfil a cada usuário ou uma página de fãs (geralmente utilizadas para promover a imagem de uma marca ou pessoa), na qual se pode acrescentar diversas informações. Os políticos, por exemplo, podem criar seu próprio perfil de maneira a aproximar-se dos eleitores, tendo em vista que

A comunicação assume uma função democrática, constituindo-se como pilar essencial do funcionamento da democracia de massas. Opções políticas de cidadãos são formadas a partir das mensagens que lhes chegam acerca das propostas, acções e ideias dos partidos políticos e dos candidatos nos atos eleitorais. Comunicação que é essencial ao diálogo, ao compromisso e à interactividade entre eleito/responsáveis políticos e cidadãos eleitores (OLIVEIRA, 2012, p. 35-36).

66 
Considerando o contexto lusófono, o português é a terceira língua mais falada no Facebook, depois das línguas inglesa e espanhola (PUBLICO, 2012). Assim, pode-se dizer que a internet diminui as distâncias por meio das redes sociais, as quais permitem partilha de informação, possibilitando que uma mensagem emitida atinja muitas pessoas.

\section{ANÁLISE E COMPARAÇÃO}

Para atingir os objetivos propostos neste artigo, foram eleitas, primeiramente, as imagens das páginas de Facebook que representam os presidentes do Brasil e de Portugal. Foram escolhidas, ainda, algumas reações às fotos principais postadas para representar os governantes e algumas reações a uma das notícias publicadas na página. Essas escolhas possibilitam estudar as atividades de imagem dos presidentes, além das interações do público com os governantes e entre si.

Em relação à atividade de imagem, é preciso apontar que o caso analisado difere das interações faladas, mas há comunicação entre os políticos e o público eleitor. O Facebook, inclusive, permite reações dos usuários em relação ao que é publicado. Os políticos comunicam-se baseados em quem acreditam ser seus coenunciadores, mesmo que se trate do povo brasileiro e português em geral, e não de alguém específico. Essas características da interação fazem com que exista atividade de imagem.

Ao observar a imagem principal da página que representa a presidente Dilma Rousseff, nota-se que há a busca de realizar uma comunicação direta com o público eleitor, mostrando a presidente abraçada com crianças, com o destaque, ao lado, do programa social criado por seu partido, conhecido como Minha Casa, Minha Vida. A imagem de perfil mostra uma presidente sorridente e com ar esperançoso, também estabelecendo aproximação com o público.

Além disso, a primeira postagem apresenta um enunciado em primeira pessoa, como se houvesse sido dito pela própria presidente, afirmando que ela é batalhadora, que ama o Brasil e o povo brasileiro e que não desiste. São todos elementos que formam, cuidadosamente, uma atividade de autoimagem, ou seja, baseado em quem são seus possíveis eleitores, a quem a presidente deve buscar persuadir, é construída para ela uma imagem de afiliação ao grupo dos brasileiros, de acordo com um perfil determinado: uma presidente forte, competente, apaixonada pelo Brasil, preocupada e envolvida com a população. 
Figura 1 - Perfil Dilma Rouseff no Facebook

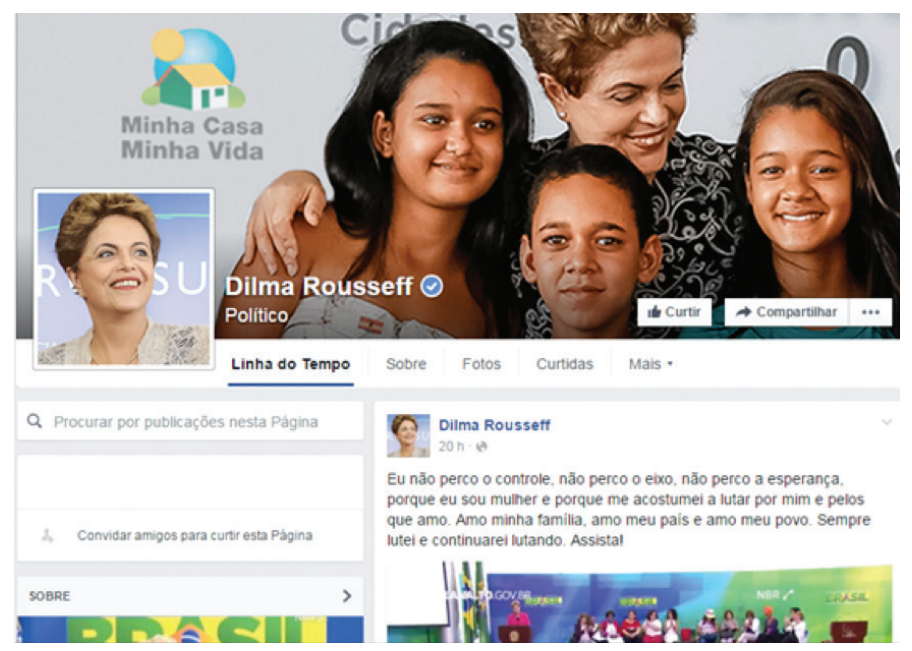

Fonte: Dilma Rousseff (Presidente). 2016. On-line.

Dessa forma, como mencionado, a instância política na qual se insere a presidente busca uma manipulação, cujo propósito é manter o poder. Assim, observa-se a tentativa de enquadrar-se em uma imagem social de presidente, segundo o que se imagina que o público eleitor vai aprovar.

Por meio do verbo no imperativo, "assista”, a interação com os membros da página é ainda mais direta. Poderia ser considerada uma forma impositiva, por não dar liberdade de ação, mas não chega a ser descortês, pois é neutralizada pelo contexto. Trata-se de um propósito persuasivo, que introduz um vídeo condizente com o enunciado antes pronunciado, o que complementa a estratégia de atividade de autoimagem. Sendo assim, as fotos, a mensagem e o vídeo que compõem a página têm o real propósito comunicativo de persuasão, procurando legitimar a imagem construída discursivamente pela governante.

Estudando a página que representa o presidente de Portugal, Marcelo Rebelo de Sousa, nota-se que também há comunicação com o público, uma vez que, por tratar-se de uma página de apoio a sua candidatura, também há intenção de persuadir os eleitores por meio da atividade de autoimagem. Pretendeu-se estabelecer uma imagem do presidente como uma pessoa séria, o que se comprova pela foto principal (chamada no Facebook de foto de capa), na qual o governante está entre militares em um provável evento, e pela foto de perfil, que mostra uma aparência rigorosa. 
Figura 2 - Perfil Marcelo Rebelo de Sousa no Facebook

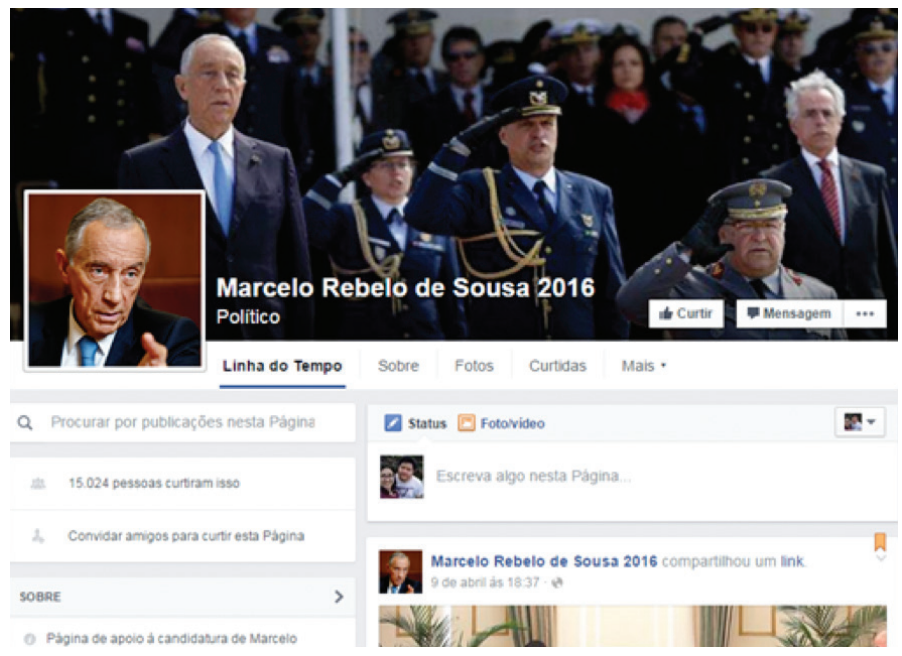

Fonte: Marcelo Rebelo de Sousa (Presidente). 2016. On-line.

Na interação que se dá entre a figura do presidente e o público, observam-se os desejos de imagem de Marcelo Rebelo de Sousa. Trata-se da busca pela afiliação, enquadrando-se no que se tem no imaginário da população portuguesa como o papel social do presidente, construindo-se como parte da nação portuguesa. Novamente, as imagens que transmitem seriedade são elementos que buscam persuadir o público eleitor e legitimar a imagem de um profissional sério e competente.

Como ocorrido na página da presidente Dilma Rousseff, a página de Marcelo Rebelo de Sousa é composta por elementos que procuram estabelecer comunicação com os possíveis eleitores, de maneira a enaltecer a imagem afiliativa (que os fazem parte do grupo de brasileiros e portugueses) do presidente de acordo com característica determinadas que agradariam, nesse caso, o povo português: um político sério, conservador e rígido.

Estabelecem-se, então, as diferenças entre as atividades de autoimagem formuladas para representar cada presidente: ao passo que no Brasil se busca construir uma imagem alegre, de esperança e de um governante que faz parte do povo, em Portugal, buscou-se uma imagem mais austera. São características que compõem traços culturais de ambos os países, tendo em vista que essas decisões foram tomadas a partir de quem são os possíveis eleitores, com intenção de persuadi-los. 
Figura 3 - Reações dos membros do Facebook à foto principal da página da presidente Dilma Rousseff

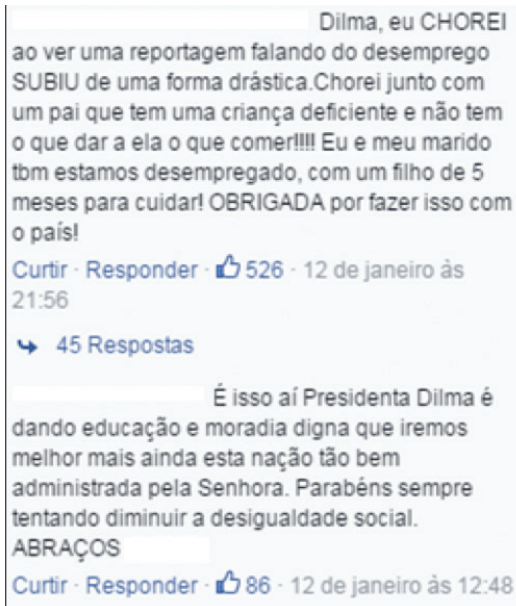

Fonte: Dilma Rousseff (Presidente). 2016. On-line.

Essa figura mostra dois comentários publicados na página que representa a presidente Dilma Rousseff. Embora as mensagens sejam abertas ao público, nessa e nas outras figuras recolhidas para exame, os nomes e fotos serão ocultados para respeitar a privacidade dos autores.

$\mathrm{Na}$ primeira mensagem, o interactante dirige-se à presidente por seu primeiro nome, Dilma, possivelmente porque a diminuição da distância ocasionada pelas redes sociais faz com que ele se sinta à vontade para chamá-la assim e, inclusive, para cobrá-la de seus afazeres como governante. Além disso, pelo teor negativo do comentário, presume-se que o falante escolheu não a chamar de uma forma considerada mais educada. A escolha de vocabulário é outro aspecto que colabora para definir esse enunciado como uma atividade de descortesia, uma vez que sua intenção é prejudicar a imagem da presidente, afirmando uma incompetência, característica considerada inadmissível em um político. Dessa forma, expressões como "forma drástica" e "chorei”, além das letras maiúsculas e dos vários pontos de exclamação, contribuem para a crítica exposta.

Ao final do primeiro comentário, dizendo "OBRIGADA por fazer isso com o país”, o falante faz uso da ironia, atribuindo para a presidente a responsabilidade do desemprego no país. Pensando em termos de máximas conversacionais, a ironia viola a máxima da qualidade, considerando que o enunciador afirma algo que sabe que não é verdadeiro. Em relação aos estudos sobre a cortesia, enunciados irônicos são estratégias que revelam uma margem para 
negociação de sentido, diminuindo o custo das imagens, tendo em vista que se trata de uma técnica indireta, ou seja,

Se você precisa ofender, ao menos o faça de modo que não entre em conflito com os Princípios de Cortesia, mas que permita que o ouvinte reconheça a ofensa indiretamente, por meio de uma implicatura. ${ }^{2}$ (LEECH, 1983, p. 82, tradução nossa).

Ainda assim, essa estratégia pode ser considerada descortês quando sua intenção é danificar a imagem do interlocutor. Além disso, trata-se de um mecanismo que faz o ouvinte ser vítima de uma mentira, o que remete ao caráter de descortesia do enunciado irônico.

Ao produzir um enunciado descortês, o falante prejudica a imagem de seu destinatário, mas costuma prejudicar a sua própria imagem no processo. Nesse caso, por não se tratar de uma interação falada, o que pode ocorrer é a danificação da imagem do falante perante o grupo de pessoas que defende a presidente. Por outro lado, o comentário pode ser considerado como positivo por aqueles que concordam com o enunciador, como expresso pelo número de "curtidas" (reação permitida pelo Facebook).

Já no segundo comentário, observa-se uma atividade de cortesia, na qual se busca valorizar a imagem da presidente. Primeiramente, o falante dirige-se a ela de maneira respeitosa, chamando-a de "Presidenta Dilma" e de "senhora". Afirma, ainda, que a pátria é "bem administrada”, elogio que reforça a imagem de boa governante. Ao fortalecer a imagem de Dilma Rousseff, o falante enaltece sua própria imagem, colocando-se como simpático e educado.

Figura 4 - Reação dos membros do Facebook à foto principal da página do presidente Marcelo Rebelo de Sousa

\footnotetext{
Senhor Presidente da República de Portugal, Exª é com todo o respeito que me dirijo (sabendo que não vai ler) mas deixo aqui o meu desejo expresso, Continue a sua caminhada olhando para TODOS. Sendo V.2 Ex. ${ }^{2}$ um católico praticante sabe que aos olhos de Deus todos somos iguais ... mesmo que uns tenham nascido em berço de ouro e muitos desprotegidos da sorte em mizeros buracos...

Não comungo da familia política, nem votei em $\mathrm{V}$. Ex. mas reitero votos de um mandato que abarque "TODOS OS PORTUGUESES". Curtir - Responder - 27 de março às 10:01
}

Fonte: Marcelo Rebelo de Sousa (Presidente). 2016. On-line.

2 "if you must cause offence, at least do so in a way which doesn't overtly conflict with the PP, but allows the hearer to arrive at the offensive point of your remark indirectly, by way of implicature”. 
A mensagem publicada na página que representa o presidente Marcelo Rebelo de Sousa mostra atividade de cortesia, expressa por elementos como os pronomes de tratamento respeitosos e escolha de vocabulário: "com todo respeito", "não comungo" em vez de "discordo". Trata-se de uma cobrança feita ao presidente de Portugal por um enunciador que afirma discordar dele e não o ter apoiado nas eleições. Ainda assim, essa cobrança é colocada de maneira sutil e educada. Dessa forma, pode-se afirmar que o falante teve a preocupação de ser cortês, ou seja, de escolher elementos linguísticos que construíssem um enunciado capaz de preservar a imagem do presidente, mesmo em uma situação possivelmente ameaçadora. Por meio desse gesto, a imagem do enunciador é enaltecida, uma vez que ele se mostra uma pessoa educada, traço valorizado em sociedade.

Objetivando persuadir o presidente, o enunciador faz uso do fato dele ser católico, temente a Deus, para apontar que, como cristão, ele deve lembrar que todos os cidadãos são portadores dos mesmos direitos, independentemente da situação financeira. Ao passo que essa afirmação colabora com o propósito comunicativo do falante, pode-se considerar como um elemento que colabora para preservar a imagem do presidente, mesmo em meio à cobrança, por relembrar a religião de Marcelo Rebelo de Sousa em um país cristão como Portugal.

Podem-se observar diferenças entre essa mensagem e aquela publicada na página que representa a presidente Dilma Rousseff. O enunciador que escreveu para a presidente do Brasil não teve a preocupação em ser cortês e em preservar as imagens dos interactantes, mas, sim, objetivou ameaçar a imagem de Dilma Rousseff, possivelmente porque seu propósito comunicativo não era manter a harmonia, mas causar impacto.

Figura 5 - Comentários em resposta à notícia publicada na página da presidente Dilma Rousseff

\footnotetext{
Parabéns Dilma ! O povo brasileiro te ama ,é muito amor que

este partido tem pelos os menos favorecidos, porque antes a miséria era

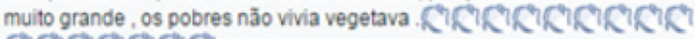

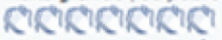

Curtir-Responder-B24-8 de abril às $18: 39$

^ Ocultar 16 respostas

Verdade agora não tem gente passando fome e desempregados, eu nunca vi tanto morador de rua em todos oa anos anteriores... Nunca vi tantas pessoas pedindo dinheiro e vivendo na misérialli Que pais vc vive DQ no Brasil não deve ser... Curtir-Responder - $\mathbf{B} 7$ - 9 de abril às 05:36

Fonte: Dilma Rousseff (Presidente). 2016. On-line.
} 
$\mathrm{Na}$ figura acima, a primeira mensagem é destinada à presidente Dilma Rousseff e a que segue é uma resposta à primeira. O primeiro enunciador dirige-se à presidente por "Dilma", mas observa-se nessa escolha um efeito de sentido diferente da outra mensagem que também a chamou assim. Nesse caso, por meio do teor positivo do texto, sabe-se que se trata de uma tentativa de sentir-se mais próximo, e não de uma falta de respeito, o que pode gerar uma atividade de cortesia.

Manifestações corteses também podem ser observadas em outros elementos, como no elogio, na palavra "parabéns" e nos chamados emoticons, recurso visual permitido pelo Facebook, que representa mãos aplaudindo. Assim, pode-se dizer que há a busca pela valorização da imagem da presidente. Como a cortesia permite mútuo benefício das imagens, ao ser cortês, o falante enaltece também sua imagem.

O comentário que segue traz uma resposta à mensagem anterior, que, inicialmente, devido à palavra "verdade", parece tratar-se de um falante que concorda com o que foi dito. No entanto, ao continuar a leitura do comentário, percebe-se que se trata de uma ironia, comprovada pela opinião real do enunciador - "eu nunca vi tanto morador de rua em todos os anos anteriores" -, o que possibilita uma negociação de sentidos, de maneira a não violar a atividade de cortesia diretamente, amenizando a ameaça por meio de um ato de fala indireto. No entanto, como dito, esse enunciado pode ser interpretado como descortês, uma vez que viola a máxima da qualidade e ameaça as imagens. A escolha em violar tal máxima foi feita com uma intenção específica: além de ameaçar a imagem do enunciador da primeira mensagem, procurou danificar a imagem da presidente, uma vez que o falante afirma que nunca havia vivenciado um período tão precário no Brasil. A escolha do vocabulário - “miséria", "fome”, "moradores de rua” - contribui com a ameaça à imagem, o que faz com que exista atividade de descortesia.

A mensagem termina com uma pergunta retórica que ameaça as imagens do enunciador dessa mensagem e do enunciador do comentário anterior, uma vez que é também descortês, pois se trata de uma indagação da qual já se sabe a resposta. Seu real propósito comunicativo não é obter a informação acerca do país no qual o interlocutor vive, mas sim acusá-lo de ignorância quanto à realidade do Brasil. 
Figura 6 - Comentários em resposta à notícia publicada na página do presidente Marcelo Rebelo de Sousa

\footnotetext{
O povo português é engraçado. Se se faz é porque se faz. se se fala é porque se fala, se se trabalha e se é genuino e activo é porque .... Valha-me Deus!l O Sr Presidente é ele mesmo com virtudes e defeitos e isso é que é importante. Um ser humano excelente que não embarcou no que os outros queriam por isso GANHOU com mérito, inteligência e sensibilidade. Curtir - Responder - B1 - Ontem às $13: 28$

concordo quase integralmente consigo, Mas não posso deixar de ter a minha opinião. Aliás, como referi, tenho uma enorme admiração por ele devido às inúmeras capacidades que the reconheço.

Curtir - Responder - Ontem às 14:35

Fonte: Marcelo Rebelo de Sousa (Presidente). 2016. On-line.
}

Nessa figura, a primeira mensagem começa dizendo que "o povo português é engraçado", mas, devido ao contexto criado no comentário, sabe-se que não se trata de um elogio, e sim de uma crítica, afirmando que se trata de um povo que nunca está satisfeito. Na continuação, há atividade de valorização da imagem do presidente, afirmando que se trata de um homem íntegro e verdadeiro.

Em resposta, a segunda mensagem discorda da primeira de maneira cortês, ou seja, preservando as imagens do enunciador e do coenunciador. O falante que escreveu esse comentário teve a preocupação de mostrar-se educado, afirmando que tem direito de ter sua opinião, mas de maneira que não ameace a imagem de seu interlocutor, termina o comentário, também, com atividade de valorização da imagem do presidente - "enorme admiração" -, o que contribui para manter a harmonia na comunicação, por tratar-se de uma opinião comum à do coenunciador.

Comparando com o que ocorre na página que representa a presidente do Brasil, na qual também há discordância, observa-se a diferença de que o primeiro falante não se preocupou em preservar as imagens de nenhum dos interactantes, pois seu propósito era enfatizar a crítica; ao contrário do enunciador português, que mesmo não concordando, buscou a atividade de cortesia.

\section{CONSIDERAÇÕES FINAIS}

Neste estudo, foram analisadas algumas interações entre usuários da rede social Facebook e a maneira com a qual os presidentes do Brasil e de Portugal, agentes da instância política, fazem uso dessa ferramenta midiática para persuadir a instância cidadã, a quem compete a eleição dos candidatos à presidên- 
cia. A análise buscou identificar e examinar manifestações de atividade de imagem, de cortesia e de descortesia, tendo em vista seus propósitos comunicativos.

Dessa forma, nas interações brasileiras, observou-se, primeiramente, uma atividade de autoimagem para legitimar a imagem pública da presidente como alguém preocupada com a população. Em relação às atividades de cortesia, os brasileiros que defendem Dilma Rousseff mostraram-se corteses, valorizando a imagem da governante e a própria imagem como consequência. Nas atividades de descortesia, por sua vez, os enunciadores não pareceram preocupados em preservar as imagens, mostrando que a real intenção era denegrir a presidente, sem manter a harmonia.

$\mathrm{Na}$ página da rede social que representa o presidente português, a atividade de autoimagem ocorreu de maneira distinta, buscando legitimar a imagem pública de um governante sério. Ainda assim, pode-se dizer que o propósito comunicativo foi o mesmo: persuadir o público eleitor, o que difere são as táticas de persuasão, considerando que essas são eleitas tendo em mira quem são os interlocutores. Sendo assim, pressupõe-se que o povo brasileiro prefere eleger uma figura mais descontraída, ao passo que o povo português escolhe uma figura mais austera, decisões que representam traços culturais e marcas identitárias de ambas as nações.

Nas demais interações publicadas na página do presidente Marcelo Rebelo de Sousa, foram observadas atividades de cortesia até nas discordâncias, mostrando a preocupação de preservar e/ou enaltecer as imagens de todos os interactantes, característica que não ocorreu nas interações brasileiras analisadas.

Assim, este artigo trabalhou com manifestações de linguagem de dois países lusófonos, tendo em vista que uma mesma língua pode ser utilizada de maneiras distintas, representando diferentes traços culturais e identitários.

\section{Politeness, impoliteness and face work: an analysis of Facebook comments published in the pages of Brazil and Portugal presidents}

\section{Abstract}

The use of languages can also be guided by cultural factors. Considering that, it is known that the Portuguese language, for example, has its own characteristics expressed in the different countries in which it is spoken. Thus, this article sought to point out the differences in the use of this language concerning politeness, impoliteness and face work applied in Facebook comments related to politics. Those comments were made in Brazilian and European Portuguese, highlighting the connection between language, culture and identity. 


\section{Keywords}

Politeness. Lusophony. Political discourse.

\section{REFERÊNCIAS}

BRAVO, D. ¿Imagen positiva vs. imagen negativa?: Pragmática social y componentes de face. Oralia: análisis del discurso oral, v. 2, p. 155-184, 1999.

BRAVO, D. Panorámica breve acerca del marco teórico y metodológico. In: BRAVO, D.; BRIZ, A. (Eds.). Pragmática sociocultural: estudios sobre el discurso de cortesía en español. Barcelona: Editorial Ariel, 2004a, p. 5-11.

BRAVO, D. Tensión entre universalidad y relatividad em las teorias de la cortesía. In: BRAVO, D.; BRIZ, A. (Eds.). Pragmática sociocultural: estudios sobre el discurso de cortesía en español. Barcelona: Editorial Ariel, 2004b, p. 15-37.

BRITO, R. H. P. Papel do português em Timor-Leste. In: ÁCCAMO, C. Á. (Coord.). Língua, desigualdade e formas de hegemonia. Monográfico em Agália. Revista de Estudos na Cultura, v. 104, p. 79-99, 2013.

BROWN, P.; LEVINSON, S. C. Politeness: some universals in language usage. Cambridge: Cambridge University Press, 1987.

CHARAUDEAU, P. Discurso político. Tradução Fabiana Komesu e Dilson Ferreira da Cruz. São Paulo: Contexto, 2015.

GOFFMAN, E. Interaction ritual: essays on face-to-face behaviour. New York: Garden City, 1967.

HALL, S. The question of Cultural Identity. In: HALL, S., HELD, D., HUBERT, D.; THOMPSON, K. (Eds.). Modernity: An Introduction to Modern Societies. Massachusetts: Blackwell Publishers, 1996, p. 596-629.

HERNÁNDEZ FLORES, N. La cortesía como la búsqueda del equilibrio de la imagem social. In: BRAVO, D.; BRIZ, A. (Eds.). Pragmática sociocultural: estudios sobre el discurso de cortesía en español. Barcelona: Editorial Ariel, 2004, p. 95-108.

LEECH, G. Principles of pragmatics. New York: Routledge, 1983.

OLIVEIRA, C. Governar é Comunicar. Porto: Omnisinal Edições, 2012.

PUBLICO. Português é a terceira língua mais falada no Facebook. 2012. Disponível em: <http://p3.publico.pt/actualidade/media/5459/portugues-e-terceira-lingua-mais-falada-no-facebook>. Acesso em: 12 jan. 2017.

Recebido em 24-02-2017.

Aprovado em 27-03-2017. 